\title{
As dimensões da avaliação em cursos online: reflexões e importância
}

\section{Dimensions assessment in online courses: reflections and importance}

\author{
Adriana Aparecida de Lima Terçariol \\ Universidade do Oeste Paulista, UNOESTE/SP (Brasil) \\ Universidade Nove de Julho, UNINOVE/SP (Brasil) \\ Elisangela Aparecida Bulla Ikeshoji \\ Jeong Cir Deborah Zaduski \\ Ana Lucia Farão Carneiro Siqueira \\ Fernanda Sutkus de Oliveira Mello \\ Universidade do Oeste Paulista, UNOESTE/SP (Brasil)
}

\section{Resumo}

Os cursos desenvolvidos na modalidade a distância, via Internet, pelo seu caráter diferenciado e pelos desafios que enfrentam, devem ser acompanhados e avaliados em todos os seus , de forma sistemática, contínua e abrangente. Uma avaliação constante desses cursos se torna útil e necessária para o seu aprimoramento constante e sua continuidade. Este artigo apresenta como principal finalidade descrever e analisar as dimensões da avaliação em cursos online, especialmente, implementados no Ensino Superior. A metodologia escolhida para desenvolver este estudo se pautou em estudos de revisão bibliográfica sistemática, na base de dados Scielo, contou também com apoio de trabalhos realizados por estudiosos sobre o tema e as experiências vivenciadas no cotidiano de trabalho das pesquisadoras. Como principais resultados, o estudo aponta que é fundamental que se perceba que os cursos a distância que se desenvolvem de forma exclusivamente online, apresentam um caráter diferenciado e pelos desafios que enfrentam, devem ser acompanhados e avaliados em todos os seus aspectos, de forma sistemática, contínua e abrangente. Uma avaliação constante desses cursos auxilia em sua continuidade, pois dela emergem as deficiências e as possíveis ações no sentido de aprimoramento do processo. Nesse sentido, o processo de avaliação nesse contexto deve contemplar minimamente quatro dimensões: a avaliação da aprendizagem, a avaliação do material didático, a avaliação da infraestrutura tecnológica e a avaliação institucional.

Palavras-chave: educação a distância; avaliação; ensino superior.

\section{Abstract}

Courses developed via Internet, by their distinctive character and the challenges they face, should be monitored and evaluated in all their aspects in a systematic, continuous and comprehensive manner. A constant evaluation of these courses is useful and necessary for their 
improvement and continuity. This article analyzes the assessment of different dimensions in online courses, especially those implemented in higher education. The methodology chosen to develop this study is based on a systematic literature review, Scielo database, with the support of works done by scholars on the subject and the experiences of researchers in their daily work. The study points out that it is essential to realize that distance learning courses that develop exclusively online have a distinctive character, and the challenges they face should be monitored and evaluated in a refined, systematic, continuous and comprehensive way. A constant evaluation of these courses assists in the identification of deficiencies and possible actions for improvement. In this sense, the evaluation process here should include at least four dimensions: assessment of learning, assessment of learning materials, assessment of technological infrastructure, and institutional assessment.

Keywords: distance education; evaluation; higher education.

Os cursos desenvolvidos na modalidade a distância, via Internet, pelo seu caráter diferenciado e pelos desafios que enfrentam, devem ser acompanhados e avaliados em todos os seus aspectos, de forma sistemática, contínua e abrangente. É fundamental compreender a importância da avaliação constante sobre as dimensões de um curso online. Uma avaliação contínua desses cursos se torna útil e necessária para o seu aprimoramento constante e sua perpetuidade.

A partir de um processo avaliativo, emergem as deficiências e as possíveis ações no sentido de corrigi-las. Nesse sentido, acredita-se que o processo de avaliação em cursos online deva contemplar minimamente quatro dimensões: a avaliação do processo de aprendizagem, a avaliação do material didático, a avaliação da infraestrutura tecnológica e a avaliação institucional. A avaliação contínua em Educação a Distância (EaD), segundo Laguardia, Casanova e Machado (2010, p. 120), deve ser “[...] integrada à gestão educacional que seja capaz de apontar os limites das estratégias pedagógicas e recursos midiáticos utilizados em distintos grupos de estudantes, com vistas a subsidiar a sua reformulação e adequação às novas demandas que surgem”, de modo que os processos possam ser melhorados, tanto durante, como, posteriormente.

Nessa perspectiva, este estudo apresenta como principal objetivo descrever e analisar as dimensões da avaliação em cursos online, especialmente, implementados em Instituições de Ensino Superior (IES). Para tanto, esses elementos serão abordados com mais detalhes, no decorrer deste artigo. Assim, também se apresenta o percurso metodológico adotado que desmembra e organiza este estudo.

\section{PERCURSO METODOLÓGICO}

O percurso escolhido para desenvolver este artigo se pautou em estudos de revisão bibliográfica sistemática, na base de dados Scielo ${ }^{1}$, contou também com apoio de trabalhos realizados por estudiosos sobre o tema, e as experiências vivenciadas no 
cotidiano de trabalho das pesquisadoras. A escolha por este tipo de pesquisa se deu em função de proporcionar aos pesquisadores o contato com os conhecimentos já produzidos na área. Essa ação vai ao encontro do que observa Moura, Ferreira e Paine (1998, p. 35) "a escolha de um tema de pesquisa exige que se tenha familiaridade com o que já foi pesquisado sobre aquele tema”.

Nese caso, essa aproximação mais estreita com o tema, ocorreu por meio do contato com as publicações disponibilizadas na base de dados Scielo. A escolha por essa base de dados se justifica devido a ela estar disponível aos usuários, com acesso aberto, online, possibilitando o acesso a textos completos publicados em periódicos nacionais, abrangendo várias áreas do conhecimento e uma vasta quantidade de revistas indexadas.

A partir desse procedimento, realizamos o levantamento de publicações científicas, produzidas no Brasil, entre 2006 a 2015, que discutem a questão da avaliação, nas suas dimensões de ensino e aprendizagem; material didático; infraestrutura tecnológica e avaliação institucional, em cursos online.

Portanto, a escolha do descritor "cursos online" se deu em função de não existir nenhuma publicação quando a busca foi realizada com os descritores "aprendizagem em cursos online", "material didático em cursos online", "estrutura tecnológica em cursos online", "avaliação institucional em cursos online". As tabelas apresentadas, a seguir, demonstram o resultado desse levantamento.

Tabela 1. Busca inicial dos artigos científicos na Base Scielo

\begin{tabular}{|c|c|c|}
\hline Descritor & Artigos disponibilizados & Artigos selecionados \\
\hline "Cursos Online" & 33 & 8 \\
\hline Total & 33 & 8 \\
\hline
\end{tabular}

Fonte. SciELO - Scientific Electronic Library Online (http://www.scielo.org/php/index.php). Nota: Dados trabalhados pelas autoras.

Após a localização na base Scielo, dos 33 artigos, realizou-se a leitura de todos os resumos, com o propósito de encontrar discussões e reflexões sobre o tema "Avaliação em Cursos Online", de maneira a encontrar, mais especificamente, em suas abordagens as dimensões: avaliação do processo de aprendizagem; avaliação do material didático; avaliação da infraestrutura tecnológica e avaliação institucional.

Após a leitura dos resumos foram então selecionados 8 artigos para um estudo mais aprofundado, pois o resumo apresentava um viés próximo do objetivo desta pesquisa. Foram lidos e analisados na íntegra, assim como feito o fichamento e organizada as ideias para utilização neste trabalho, conforme organizado na tabela 2, segundo ordem alfabética do autor (es)/artigo; resumo e revista/ano de publicação. 
Tabela 2. Artigos selecionados - Descritor "Cursos Online"

\begin{tabular}{|c|c|c|c|}
\hline $\mathrm{N}^{0}$ & Autor (es) / Artigo & Resumo & $\begin{array}{l}\text { Revista / Ano } \\
\text { Publicação }\end{array}$ \\
\hline 01 & $\begin{array}{l}\text { Abreu-E-Lima, D. M. de; } \\
\text { Alves, M. N. O feedback e sua } \\
\text { importância no processo de } \\
\text { tutoria a distância. }\end{array}$ & $\begin{array}{l}\text { A qualidade do diálogo entre } \\
\text { professor e estudante é um } \\
\text { processo de fundamental } \\
\text { relevância que pode proporcionar } \\
\text { autonomia ao estudante, num } \\
\text { processo de aprendizagem. } \\
\text { Sendo, portanto, um processo } \\
\text { que requer a utilização do } \\
\text { feedback em ambientes virtuais de } \\
\text { aprendizagem. }\end{array}$ & $\begin{array}{l}\text { Pro-Posições / } \\
2011 .\end{array}$ \\
\hline 02 & $\begin{array}{l}\text { Funo, L. B. A.; Elstermann, } \\
\text { Anna-Katharina; Souza, M. } \\
\text { G. de. Fóruns no ambiente } \\
\text { Teleduc: reflexões sobre o papel } \\
\text { dos mediadores e estratégias de } \\
\text { gerenciamento de debates. }\end{array}$ & $\begin{array}{l}\text { Proporcionar a reflexão de seus } \\
\text { cursistas acerca da fundamentação, } \\
\text { das práticas e das tecnologias de } \\
\text { ensino e aprendizagem e dos papéis } \\
\text { relevantes para o mediador de } \\
\text { educação a distância. }\end{array}$ & $\begin{array}{l}\text { Revista } \\
\text { Brasileira de } \\
\text { Linguística } \\
\text { Aplicada / } 2015 .\end{array}$ \\
\hline 03 & $\begin{array}{l}\text { Laguardia, J.; Casanova, A.; } \\
\text { Machado, R. A. experiência } \\
\text { de aprendizagem on-line } \\
\text { em um curso de qualificação } \\
\text { profissional em saúde. }\end{array}$ & $\begin{array}{l}\text { Apontam questões importantes a } \\
\text { serem consideradas na concepção } \\
\text { e gestão de cursos online, como } \\
\text { a necessidade de readequação } \\
\text { periódica da proposta pedagógica } \\
\text { do curso para atender as demandas } \\
\text { dos estudantes e tutores quanto } \\
\text { à organização e atualização dos } \\
\text { conteúdos, os meios de acesso ao } \\
\text { material e a implementação de } \\
\text { atividades avaliativas compatíveis } \\
\text { com a experiência de trabalho. }\end{array}$ & $\begin{array}{l}\text { Trabalho } \\
\text { Educação e } \\
\text { Saúde / } 2010 .\end{array}$ \\
\hline 04 & $\begin{array}{l}\text { Miranda, F. D. S. S. Integração } \\
\text { das tecnologias digitais da } \\
\text { informação e comunicação } \\
\text { em contextos educacionais: } \\
\text { análise de três momentos de } \\
\text { um curso oficial de formação de } \\
\text { professores. }\end{array}$ & $\begin{array}{l}\text { As relações entre ensino público, } \\
\text { tecnologias digitais e letramentos } \\
\text { na contemporaneidade, apontaram } \\
\text { para diversas articulações entre } \\
\text { ensino e tecnologias, e parece não } \\
\text { existir separações demarcadas } \\
\text { entre eles. }\end{array}$ & $\begin{array}{l}\text { Trabalho } \\
\text { Linguística } \\
\text { Aplicada / } 2014 .\end{array}$ \\
\hline
\end{tabular}




\begin{tabular}{|c|c|c|c|}
\hline $\mathrm{N}^{0}$ & Autor (es) / Artigo & Resumo & $\begin{array}{l}\text { Revista / Ano } \\
\text { Publicação }\end{array}$ \\
\hline 05 & $\begin{array}{l}\text { Oliveira, G. P. de. Estratégias } \\
\text { multidimensionais para a } \\
\text { avaliação da aprendizagem em } \\
\text { cursos on-line. }\end{array}$ & $\begin{array}{l}\text { O caráter multidimensional } \\
\text { que as tecnologias oferecem } \\
\text { apresenta ser capaz de dar } \\
\text { conta do caráter complexo do } \\
\text { conhecimento pertinente, levando } \\
\text { em consideração as múltiplas } \\
\text { possibilidades de interação, os } \\
\text { diferentes tempos e espaços de } \\
\text { aprender e ensinar, e as interfaces } \\
\text { correspondentes, bem como as } \\
\text { abordagens interdisciplinares } \\
\text { presentes no ambiente } \\
\text { colaborativo. }\end{array}$ & $\begin{array}{l}\text { Ensaio: } \\
\text { Avaliação } \\
\text { Políticas } \\
\text { Públicas em } \\
\text { Educação / } \\
2010 .\end{array}$ \\
\hline 06 & $\begin{array}{l}\text { Rozenfeld, C. C. de F. } \\
\text { Planejamento de cursos } \\
\text { online para professores de } \\
\text { alemão: parâmetros em mapa } \\
\text { conceitual. }\end{array}$ & $\begin{array}{l}\text { O planejamento de cursos online } \\
\text { deve contar com a participação } \\
\text { e colaboração do professor } \\
\text { que se envolverá diretamente } \\
\text { com o processo do ensino e de } \\
\text { aprendizagem, inclusive para a } \\
\text { preparação do material didático. }\end{array}$ & $\begin{array}{l}\text { Pandaemonium } \\
\text { Germanicum / } \\
\text { 2013. }\end{array}$ \\
\hline 07 & $\begin{array}{l}\text { Santos, A. N. dos; Mercado, } \\
\text { L. P. L. Arquivamento e } \\
\text { comunicação de imagens } \\
\text { radiológicas na formação } \\
\text { médica online. }\end{array}$ & $\begin{array}{l}\text { Trata sobre as possibilidades } \\
\text { de utilização dos recursos de } \\
\text { arquivamento e comunicação } \\
\text { de imagens nas salas de aula e à } \\
\text { distância no processo de formação } \\
\text { médica através da telemedicina. Os } \\
\text { aspectos de formação docente dos } \\
\text { médicos, especialmente para atuar } \\
\text { em ambientes online, definição } \\
\text { de metodologias de avaliação, } \\
\text { interação entre os sujeitos } \\
\text { envolvidos. }\end{array}$ & $\begin{array}{l}\text { Revista } \\
\text { Brasileira } \\
\text { de Educação } \\
\text { Médica / } 2010 .\end{array}$ \\
\hline 08 & $\begin{array}{l}\text { Teixeira, D. E. et al. Avaliação } \\
\text { institucional em Ciências } \\
\text { Biológicas nas modalidades } \\
\text { presencial e a distância: } \\
\text { percepção dos egressos. }\end{array}$ & $\begin{array}{l}\text { Estudantes de um curso de } \\
\text { graduação a distância consideram } \\
\text { sua formação satisfatória, em } \\
\text { contrapartida estudantes do } \\
\text { mesmo curso, mas na modalidade } \\
\text { presencial fazem críticas em vários } \\
\text { aspectos. A importância da análise } \\
\text { que se concretizou por meio da } \\
\text { avaliação institucional. }\end{array}$ & $\begin{array}{l}\text { Ensaio: } \\
\text { Avaliação } \\
\text { Políticas } \\
\text { Públicas em } \\
\text { Educação / } \\
2015 \text {. }\end{array}$ \\
\hline
\end{tabular}

Fonte. SciELO - Scientific Electronic Library Online (http://www.scielo.org/php/index.php). Nota: Dados trabalhados pelas autoras. 
A partir dessa organização, e tendo por base as análises realizadas, desenvolveuse os tópicos que compõe este artigo, conforme será abordado a seguir.

\section{AVALIAÇÃO DA APRENDIZAGEM E/OU RECUPERAÇÃO: PROCESSO CONTÍNUO}

Em se tratando da avaliação da aprendizagem, na educação a distância, é comum se reproduzir os modelos utilizados na educação presencial. Porém, precisase compreender que, é preciso reorientar o processo avaliativo da aprendizagem, quando esta é considerada pela perspectiva a distância, principalmente, porque as propostas e metodologias se desmembram de forma distinta. Um dos fatores que evidencia essa distinção, em relação ao ensino presencial, refere-se à ausência física do professor, o que implica uma alteração quanto à forma como a aprendizagem se desenvolve, seja pelo que é ministrado (e como é ministrado), seja pelo que se propõe produzir em termos de ensino prático.

No entanto, a ausência física do professor não retira o papel deste de mediador no processo de ensino e de aprendizagem, tanto que esta é uma tarefa fundamental, embora difícil e crucial, em se tratando de educação em modelo não presencial (Funo, Elstermann e Souza, 2015).

Todavia, isso significa que, do estudante que aprende a distância, espera-se que ele seja capaz de desenvolver a autonomia, bem como desenvolver o senso crítico, a iniciativa para a tomada consciente de posição diante do que lê. Nesse sentido, são importantes as escolhas dos métodos avaliativos utilizados para essa modalidade de ensino, os quais precisam refletir tal expectativa.

Lembrando que as disciplinas que compõem um curso online são desenvolvidas por meio de atividades a distância, exceto aquelas destinadas à avaliação final da aprendizagem, prevista como obrigatória na legislação. As atividades colocam à disposição do estudante recursos que propiciam suporte na realização de seus fazeres, possibilitando uma efetiva aquisição e revisão dos conhecimentos contidos na matriz curricular do curso: bibliotecas, laboratórios de informática, atividades em empresas juniores, dentre outras.

Percebe-se que vem ocorrendo mudanças quanto ao processo de avaliação de aprendizagem. Em modelos mais tradicionais de ensino, a avaliação era punitiva e somativa, baseada em notas. Mas, com as transformações ao longo dos tempos, as inovações na teoria de currículo e nas concepções do que é ensino e aprendizagem, foram surgindo novas perspectivas para os processos avaliativos, que, voltou-se para a formação de pessoas críticas. Sendo assim, a avaliação passa a ter uma importante contribuição para a inclusão, ascensão e independência dos estudantes.

Avaliar, nesse novo paradigma, é dinamizar oportunidades de ação-reflexão, num acompanhamento permanente do professor e este deve propiciar ao estudante em seu processo de aprendizagem, reflexões acerca do mundo, formando seres críticos, 
libertários e participativos na construção de verdades formuladas e reformuladas (Hoffmann, 1993, p. 134).

Dessa forma, contribui-se para que a avaliação não esteja centrada apenas no produto em si, mas nos caminhos e processos utilizados para sua realização. E, uma vez desenvolvida no estudante, habilidades de análise sobre suas produções e dos colegas de turma, favorece-se a depuração dos trabalhos produzidos, quando esses não atingem os níveis esperados.

Para Abreu-e-Lima e Alves (2011), a autonomia do estudante em EaD é algo que poder ser conseguido quando se proporciona diálogos de qualidade entre professor e estudante, assim como entre os próprios estudantes. Por isso, reforça-se novamente a questão do papel do professor ser fundamental, especialmente, nesse contexto. Nos cursos online ele acaba desempenhando diferentes papeis, sendo um deles o de desencadear e mediar o diálogo com e entre os estudantes.

Daí a importância do professor em se atentar ao que Funo, Elstermann e Souza (2015, p. 34) abordam,

[...] há distinção de dois níveis de desenvolvimento do aprendiz, o real e o potencial. $\mathrm{O}$ primeiro (real) caracteriza-se pela habilidade do aprendiz de realizar tarefas de modo independente. O segundo (potencial) caracteriza-se pelas funções potenciais que esse aprendiz pode desempenhar com a ajuda de um parceiro que exerça o papel de especialista e lhe ofereça alguma forma de suporte.

Por isso ao conhecer essa distinção, o professor nesse processo, além de estimular o diálogo, deve emitir os feedbacks, elemento fundamental para orientar os estudantes, quanto ao seu processo de aprendizagem. Assim, prevê-se para o processo continuado de avaliação da aprendizagem a oferta de feedback ao longo do processo de mediação desencadeado pelo professor, uma vez que com isso se propicia ao estudante desencadear processos reflexivos, a ponto de desenvolver e analisar suas próprias produções, percebendo a necessidade de revisão para melhor atender a proposta da atividade desenvolvida, assim como alcançar níveis mais elevados de reflexão.

Portanto, em relação ao feedback é importante considerar também que devido ao potencial do Ambiente Virtual de Aprendizagem (AVA) em registrar e tornar público para a turma de uma determinada disciplina as produções desenvolvidas pelos estudantes, torna-se possível estimular os próprios estudantes a realizarem a análise das produções dos colegas, estimulando como consequência uma postura crítica dos estudantes diante das informações e compreensões apresentadas pelos pares no AVA. Esse processo é acompanhado pelo professor, que ao final das observações trocadas pelos grupos e/ou estudantes individualmente, oferece um parecer final sobre a dinâmica vivenciada, bem como os pareceres socializados. 
Todavia, é importante que no decorrer de todo o processo de avaliação, que deve ser contínuo e constante, o professor não se esqueça da "escada de feedback" traduzida por Abreu-e-Lima e Alves (2011) que abrange:

- Esclarecer: quando o estudante realiza as atividades, participa de fóruns, momento esse praticamente em que o aluno desenvolve a linguagem escrita. Nesse momento, o professor deve esclarecer, caso o estudante não tenha atendido o objetivo da atividade proposta, assim como dar o constante feedback para contribuir no contínuo processo de aprendizagem.

- Valorizar: o professor deve aproveitar essa fase para criar um elo de confiança entre ele e o estudante. Apontar os aspectos positivos e apontar os pontos que podem ser melhorados.

- Questionar: é o momento apropriado para o professor questionar sobre algo que ficou em dúvida, com transparência e responsabilidade para que não fiquem dúvidas ou algo entendido, superficialmente.

- Sugerir: pontuar o que pode ser melhorado, contribuir para o processo de aprendizado, por parte do estudante, sugerindo e estimulando-o a ir além, não se limitando ao mínimo.

Entende-se assim, que a avaliação perde sua característica tradicional de medir o conhecimento e se volta para uma análise quanto à capacidade de reflexão das experiências, as análises recaem sobre o desenvolvimento dessa capacidade de refletir sobre a prática. Isto é, aliás, o que se propõe hoje em termos educativos, ou seja, formar sujeitos que possam se posicionar, criticamente, diante das experiências, e assim atuar de forma mais consciente diante delas.

Sendo assim, entende-se que a proposta de avaliação para a modalidade a distância na IES deve ser baseada no princípio de que deve ser levado em consideração o ritmo do estudante, assim como no desenvolvimento do aprendiz (Funo, Elstermann e Souza, 2015, p. 34). Este deve ser estimulado a desenvolver graus mais complexos de competências cognitivas, habilidades e atitudes, possibilitando-lhe alcançar os objetivos propostos. Mais que uma formalidade legal, a avaliação deve permitir ao estudante, sentir-se seguro quanto aos resultados que vai alcançando no processo de ensino e de aprendizagem.

Como um elemento essencial na educação a distância, ainda é necessário ser mais valorizado, segundo dados da pesquisa desenvolvida por Abreu-e-Lima e Alves (2011), com 154 tutores em formação da Universidade Aberta Brasileira (UAB), onde $85 \%$ deles com mestrado e doutorado, $47,6 \%$ declaram que só reconheceram a importância do feedback após o curso de formação para tutores, proporcionado pela UAB.

Outro aspecto a ser considerado neste contexto trata-se da recuperação dos conteúdos que deve acontecer de forma paralela à aquisição da aprendizagem, 
sendo estimulada a partir dos feedbacks recebidos dos colegas de turma e professor, bem como do próprio sistema, quando for o caso das atividades de autoestudo (ex.: questionários), em relação aos tópicos e/ou atividades que tenham sido respondidas incorretamente.

Para Luckesi (apud Libâneo, 1991, p. 196) "a avaliação é uma apreciação qualitativa sobre dados relevantes do processo de ensino e aprendizagem que auxilia o professor a tomar decisões sobre o seu trabalho". Assim, o processo de avaliação e recuperação dos estudos se dá de forma contínua, uma vez que os professores, monitores e coordenação do curso auxiliam na orientação e reorientação dos estudantes que apresentam dificuldades de aprendizagem.

Outro fator determinante ao longo do processo avaliativo na modalidade a distância é a frequência com que o estudante transita pelo ambiente virtual e também a qualidade das contribuições que oferece aos temas que são apresentados. Tais contribuições são contempladas, também, pelo seu nível e relevância perante as discussões desencadeadas. Nesse sentido, a participação do estudante em todas as atividades propostas, dialogando, colaborando com as discussões, entre outras ações, é uma premissa indispensável para o pleno aproveitamento do curso e, certamente, à sua aprendizagem.

Sob essa perspectiva, no ambiente virtual de aprendizagem, os estudantes são observados quanto às exposições sobre os temas, bem como quanto à realização das produções individuais e/ou coletivas, aspectos esses que compõem a sua participação e avaliação continuada nas disciplinas ou curso. Quanto às atividades referentes à apresentação dos trabalhos, são apreciados itens importantes, tais como, a relevância do conteúdo em relação aos temas que foram discutidos, se a sua construção é condizente com o nível do curso, sendo para isso necessário um bom arranjo textual, organização lógica das ideias, temas apresentados de forma sucinta e sem perder de vista os objetivos definidos e adequada fundamentação teórica.

Assim, o processo de avaliação ao ser elaborado a partir das atividades desenvolvidas no AVA, pode contar com as avaliações presenciais, agendadas antecipadamente e socializadas no calendário do curso. Geralmente, nesses cursos, preveem-se três momentos para que essa ação ocorra, são eles:

1. Avaliação ao final da disciplina: desmembrando-se em apresentação de seminários, provas dissertativas, múltipla escolha ou síntese dos conteúdos abordados.

2. Avaliação substitutiva: ocorre quando o estudante, por algum motivo, não puder realizar a avaliação final.

3. Exame: caracterizará um momento de avaliação que o estudante fará se não obtiver aprovação na composição das notas obtidas a partir das atividades avaliativas realizadas a distância e ao final da disciplina, de forma presencial. 
Ainda em se tratando do processo de avaliação da aprendizagem é importante salientar a importância da instituição garantir o sigilo e segurança nas avaliações para não expor os estudantes a situações que possam constrangê-los. Nesse sentido, a organização do curso na modalidade a distância precisa considerar que a construção do conhecimento é um processo individual e intrínseco, porém, realizar-se-á na interação do estudante com os pares, com o professor e com os recursos disponibilizados. Os estudantes utilizam dados e informações que podem ser obtidos a distância ou presencialmente, mas constroem o conhecimento e o seu desenvolvimento, de forma individualizada, de acordo com o ritmo próprio.

Portanto, proceder de forma que a avaliação seja uma crítica positiva do percurso de uma ação, solicita o envolvimento de todos que estão no processo. E mais, todos precisam estar com os mesmos ideais. Assim, esse modelo de avaliação deve ser o meio do qual, todos possam conferir como estão criando e como podem trabalhar para crescer. "[...] A avaliação é uma ferramenta da qual o ser humano não se livra. Ela faz parte de seu modo de agir e, por isso, é necessário que seja usada da melhor forma possível" (Luckesi, 2002, p. 118). A avaliação não poderá ser concebida como uma ação mecânica. "Ao contrário, terá de ser uma atividade racionalmente definida, dentro de um encaminhamento político e decisório a favor da competência de todos para a participação democrática da vida social” (Luckesi, 2008, p. 46).

\section{AVALIAÇÃO DO MATERIAL DIDÁTICO: PROCESSO CONTÍNUO}

O material didático deve ser pensado como um elemento que pela sua própria natureza seja articulado com a tecnologia. Sendo assim, caberá à equipe multidisciplinar responsável pela concepção e produção dos materiais didáticos nas diferentes mídias favorecer e colaborar para o desencadeamento de um sistema de avaliação prévia de todos os materiais, orientações e recursos tecnológicos a serem utilizados em uma disciplina ou curso, com o intuito de se realizar sua pré-testagem.

Por isso é importante, identificar com certa antecedência às necessidades de ajustes, visando ao seu aperfeiçoamento. Para a realização dessa pré-teste, com o intuito de que atinjam os objetivos esperados, pode-se socializá-los com um pequeno grupo de estudantes e/ou docentes da área, a fim de verificar possíveis equívocos e outros aspectos que tenham passado despercebidos durante a revisão da equipe multidisciplinar.

É comum as IES preverem nos projetos pedagógicos dos cursos a serem ofertados em $\mathrm{EaD}$, a depuração de todos os materiais, após a primeira oferta, caso haja necessidade, sendo para isso considerados os aspectos evidenciados por Fernandez (2009): a qualidade da linguagem adotada no material; a relevância do conteúdo tratado; a cuidadosa inclusão de atividades diversificadas, instigando a problematização e reflexão; a adequação na inserção dos elementos formais (ilustrações, a comunicação escrita e a programação visual); respeito à autoria. 
Além disso, a avaliação desse material pode também levar em conta a acolhida que teve pelos estudantes e os conhecimentos que propiciou quando de sua aplicação. Desse modo, são considerados nessa categoria da avaliação aspectos científicos, culturais, éticos e estéticos, didático-pedagógicos, motivacionais, bem como a sua capacidade dialógica e de comunicação. Ressalta Rozenfeld (2013) que para uma melhor exploração das potencialidades das tecnologias é preciso buscar, na medida do possível, uma diversificação de mídias, ou seja, planejar atividades de áudio, de vídeo, de animação, com figuras. Dessa maneira, além de motivar os participantes, possibilita também os diferentes canais de construção de sentidos e de estilos de aprendizagem.

Imagina a riqueza do que envolve o material didático e tudo que o permeia pode contribuir na formação dos estudantes de medicina, por exemplo? Na pesquisa realizada por Santos e Mercado (2010) discute-se nas aulas de telemedicina as possibilidades de utilizar os sistemas de informática para registrar as imagens de muitos exames que podem ser feitos online e a distância, assim como a emissão de laudos e das imagens radiológicas, a distância. Além disso, é abordada no estudo realizado por esses autores, a forma de arquivamento e comunicação, que deve respeitar algumas normas e regras.

Entende-se por essas e outras razões, que o material didático na educação a distância deve contar com uma elaboração e uma constante avaliação para sua adequada utilização.

\section{AVALIAÇÃO DA INFRAESTRUTURA TECNOLÓGICA: PROCESSO CONTÍNUO}

Em se tratando do pleno funcionamento da infraestrutura tecnológica adotada para a viabilização dos cursos na modalidade a distância, as instituições precisam contar com o apoio de diversos profissionais que integram uma equipe multidisciplinar, sendo alguns pertencentes à equipe do departamento de Tecnologia da Informação (TI), cujos profissionais desenvolvem processos de avaliação e revisão, periódicos e continuados, da infraestrutura de tecnologia disponível na sede da IES e respectivos polos, quando é o caso. Assim, contribuem para que toda a rede tecnológica se mantenha estável e em pleno funcionamento. Consequentemente, colaboram para o funcionamento estável e adequado do ambiente virtual, adotado para a viabilização da $\mathrm{EaD}$ na instituição.

Além disso, com o intuito de evitar a ocorrência de imprevistos que possam de alguma forma impedir o pleno funcionamento do sistema de $\mathrm{EaD}$, as equipes que compõem os Núcleos de Educação a Distância (NEaD) também colaboram com o suporte tecnológico e instrumental dos cursos, realizando backup das turmas em andamento, com vistas à sua restauração, caso necessário.

Sendo assim, as múltiplas possibilidades oferecidas pelos diferentes recursos tecnológicos adotados em um programa de $\mathrm{EaD}$ enriquecem o processo de ensino 
e de aprendizagem, pois permitem ao estudante transitar por diversos universos, identificando o foco de seu estudo sobre diversas perspectivas. De fato, a convergência dos equipamentos e a integração entre materiais impressos e online, acrescida da mediação dos professores, concorrem para que se criem ambientes de aprendizagem enriquecedores e flexíveis. Tanto que as diversas articulações que ocorre entre ensino e tecnologias, sua proximidade, ou melhor inter-relação, parece não demarcar e fazer distinção entre eles (Miranda, 2014; Oliveira, 2010).

\section{AVALIAÇÃO INSTITUCIONAL: PROCESSO CONTÍNUO}

A avaliação institucional envolve uma percepção generalizada da instituição e permite o reconhecimento de suas potencialidades e deficiências, facilitando o processo de tomada de decisões no sentido de ampliar sua performance. Esse processo avaliativo interessa à IES, porque a instituição tem como meta superar seus próprios limites e alcançar novos estágios de eficiência.

Segundo o Instituto Nacional de Estudos e Pesquisas Educacionais Anísio Teixeira (Inep, 2015) a Avaliação Institucional, divide-se em autoavaliação e avaliação externa. A autoavaliação é coordenada por uma Comissão Própria de Avaliação (CPA), constituída por cada instituição, seguindo as diretrizes e roteiro da autoavaliação institucional da Comissão Nacional de Avaliação da Educação Superior (CONAES) que é o órgão colegiado de coordenação e supervisão do Sistema Nacional de Avaliação da Educação Superior, instituído pela Lei no 10.861, de 14 de Abril de 2004 (Brasil, 2004). Já a avaliação externa é realizada por comissões designadas pelo INEP e tem como referência os padrões de qualidade para a educação superior expressos nos instrumentos de avaliação e os relatórios das autoavaliações.

De acordo com Neves (2003) torna-se essencial em um processo de avaliação institucional a:

- existência de um processo de avaliação institucional que produza efetivamente correções na direção da melhoria constante do processo pedagógico e metodológico adotado pela IES;

- análise e avaliação dos resultados obtidos pelos estudantes no processo de avaliação da aprendizagem;

- avaliação das práticas educacionais presenciais e virtuais dos formadores e dos demais agentes envolvidos na capacitação docente;

- avaliação do material didático quanto ao seu aspecto científico, cultural, ético e estético, didático-pedagógico, motivacional, sua adequação aos professoresestudantes e às TIC utilizadas, a capacidade de comunicação, entre outros; avaliação do sistema de orientação docente ou tutoria (capacidade de comunicação por meios eficientes; de atendimento aos estudantes em momentos a distância e presenciais; orientação aos estudantes; avaliação do desempenho 
dos estudantes; avaliação de desempenho como professor; papel dos núcleos de atendimento; desenvolvimento de pesquisas e acompanhamento do estágio, quando houver;

- avaliação da infraestrutura que dá o suporte tecnológico, científico e instrumental ao curso;

- avaliação do modelo de educação superior a distância adotado (uma soma dos itens anteriores combinados com análise do fluxo dos estudantes, tempo de integralização do curso, interatividade, evasão, atitudes e outros);

- metaavaliação (um exame crítico do processo de avaliação utilizado: seja do desempenho dos estudantes, seja do desenvolvimento do curso como um todo);

- existência de etapas de autoavaliação e avaliação externa.

Todavia, esse processo só pode ser feito quando se obtém um conhecimento preciso dos limites aos quais chegou e do que é possível fazer para transpô-los. No caso da EaD, em particular, a avaliação nos permitirá definir novos parâmetros para superar possíveis problemas que possam ocorrer.

A opinião do egresso é uma ferramenta importante de acompanhamento da trajetória profissional do estudante graduado, das competências adquiridas durante a Graduação e do panorama de atuação no mercado de trabalho, sendo também, principalmente, uma ferramenta para a melhoria da própria instituição (Teixeira et al., 2015, p. 160).

Os profissionais da área de tecnologia, por exemplo, podem ser avaliados quanto à capacidade em responder de forma competente e rápida aos problemas técnicos que prejudicam a operacionalização do curso. Quanto aos professores podem ser avaliados: em sua prática pedagógica, quanto ao nível de mediação, ao estabelecimento de processos interativos que produziram resultados satisfatórios, nível de atenção aos estudantes, de que forma superaram os problemas comuns em um grupo, dentre outros.

Referente aos recursos tecnológicos utilizados para viabilizar o processo de comunicação entre os sujeitos envolvidos no processo de formação podem ser avaliados quanto a sua eficiência para favorecer a interação no curso como um todo. Sendo assim, a avaliação institucional deve facilitar o processo de discussão e análise entre os participantes, divulgando a cultura de avaliação, fornecendo elementos metodológicos e agregando valor às diversas atividades do curso e da instituição como um todo. 


\section{Articulação da Autoavaliação do Curso com a Autoavaliação Institucional}

A CPA de uma IES constitui-se em órgão colegiado com atribuições de condução dos processos de avaliação internos da instituição, de sistematização e de prestação das informações solicitadas pelos órgãos de regulação da educação superior (MEC, INEP e CONAES), todas previstas no "caput" do artigo 11 da Lei 10.861/2004 (Brasil, 2004).

Sendo um órgão de atuação autônoma em relação à administração superior da IES, em respeito ao artigo 11, inciso II, da Lei 10.861/2004 (Brasil, 2004), com membros eleitos pelos seus pares, conforme seu próprio regimento. Trata-se de um processo com caráter diagnóstico, em constante aperfeiçoamento e que busca, de forma participativa, por meio do envolvimento dos segmentos da comunidade acadêmica, analisar as potencialidades e fragilidades apresentadas por cada setor da IES, de maneira que seja possível valorizar os aspectos positivos e agir com eficácia diante das situações indesejáveis que, por ventura, possam ser detectadas.

Sendo assim, na maioria das vezes e em especial nas instituições nas quais atuamos são utilizadas as seguintes instâncias para avaliação de um curso:

a. análise, pelo colegiado do curso, dos relatórios emitidos pela CPA como o relatório autoavaliação institucional e relatório de avaliação de desempenho docente;

b. socialização de informações e levantamento de sugestões e críticas alusivas aos processos e perspectivas em curso junto à congregação do curso, discutindo-se as oportunidades de melhorias e levantamento de ações corretivas e preventivas;

c. reunião com representantes de turmas para detectar problemas e levantamento de sugestões e críticas;

d. elaboração de plano de implantação, monitoramento e mensuração dos resultados obtidos, por meio das ações corretivas pelo colegiado do curso;

e. feedback para consolidação das melhorias obtidas e implantação de novas ações demandadas;

f. questionário de avaliação do corpo docente, material didático e infraestrutura do curso disponibilizado aos estudantes.

A instituição deve entender a prática do ensino como concretização de um processo de trabalho que tem como objeto às múltiplas expressões da vertente técnico-científica. Tal perspectiva exige um contínuo processo de avaliação, de modo a consubstanciar o desenvolvimento das práticas do saber. Em resumo, o curso na modalidade a distância deve utilizar-se, de forma sistemática para análise, os relatórios emitidos pela CPA e estar sob constante autoavaliação. 


\section{CONSIDERAÇÕES FINAIS}

Uma avaliação constante dos cursos concebidos na modalidade a distância, que difere da modalidade exclusivamente tradicional, auxilia em sua continuidade, pois dela emergem as deficiências e as possíveis ações no sentido de aprimoramento do processo. Porém, não somente os aspectos possíveis de serem melhorados devem ser contemplados, mas aqueles que são muito bem avaliados, uma vez que desses podem ser extraídas pistas que auxiliam na melhora de outros aspectos e/ou subsidiam para analisar os existentes.

No entanto, o processo de avaliação nesse contexto deve contemplar minimamente as quatro dimensões abordadas: a avaliação da aprendizagem, a avaliação do material didático, a avaliação da infraestrutura tecnológica e a avaliação institucional.

Portanto, o estudo desenvolvido aponta que é fundamental que se compreenda que os cursos na modalidade a distância que se desenvolvem de forma exclusivamente online, apresentam um caráter diferenciado e pelos desafios que enfrentam, devem ser, após sua concepção e criação, acompanhados e avaliados, em todos os seus aspectos, de forma sistemática, contínua e abrangente, por todos os envolvidos nesse processo.

\section{NOTAS}

1. Acesso a base de dados Scielo: http://www.scielo.org/php/index.php. É uma base com origem no Brasil, existe há 15 anos, abrangendo outros 15 países. É um programa que visa melhorar a qualidade dos periódicos científicos, visto que indexa e publica em acesso aberto.

\section{REFERÊNCIAS BIBLIOGRÁFICAS}

Abreu-e-Lima, D. M. de, e Alves, M. N. (2011). O feedback e sua importância no processo de tutoria a distância. ProPosições, 22(2), 189-205. Recuperado de: http://www.scielo.br/scielo. php? script $=$ sci arttext\&pid $=$ So103$23072011000200013 \& \ln g=$ en\&nrm=iso

Brasil. Ministério da Educação e Cultura (2004). Lei 10.861 de 14 de abril de 2004. Recuperado de: http://www.planalto.gov br/ccivil 03/ ato2004-2006/2004/lei/ $10.861 . \mathrm{htm}$

Fernandez, C. T. (2009). Os métodos de preparação de material impresso para
EaD. In F. M. Litto, M. Formiga, (Orgs.), Educação a distância: o estado da arte. (395-402). São Paulo: Pearson Education do Brasil.

Funo, L. B. A., Elstermann, A., e Souza, M. G. de. (2015). Fóruns no ambiente Teleduc: reflexões sobre o papel dos mediadores e estratégias de gerenciamento de debates. Rev. bras. linguist. apl., 15(1), 31-59. Recuperado de: http://www.scielo.br/scielo. php? script $=$ sci arttext\&pid $=\mathrm{S} 1984$ $63982015000100031 \& \operatorname{lng}=$ en\&nrm $=$ iso 
Hoffmann, J. (1993). Avaliação mediadora: uma prática em construção da pré-escola à universidade. Porto Alegre: Mediação.

Inep. Instituto Nacional de Estudos e Pesquisas Educacionais Anísio Teixeira (2015). Avaliação das Instituições de Educacão Superior. Recuperado de: http://portal.inep.gov.br/superioravaliacao institucional

Laguardia, J., Casanova, A., e Machado, R. (2010). A experiência de aprendizagem on-line em um curso de qualificação profissional em saúde. Trab. educ. saúde, 8(1), 97-122. Recuperado de: http://www.scielo.br/scielo. php? script $=$ sci arttext\&pid=S1981 77462010000100006\&lng=en\&nrm =iso

Libâneo, J. C. (1991). Didática. São Paulo: Cortez.

Luckesi, C. C. (2002). Avaliação da aprendizagem escolar: estudos e proposições. São Paulo: Cortez.

Luckesi, C. C. (2008). Avaliação da aprendizagem escolar: estudos $e$ proposições. São Paulo: Cortez.

Miranda, F. D. S. S. (2014). Integração das tecnologias digitais da informação e comunicação em contextos educacionais: análise de três momentos de um curso oficial de formação de professores. Trab. linguist. apl. .53(1), 55-77. Recuperado de: http://www.scielo.br/scielo, php? script $=$ sci arttext\&pid $=$ S010318132014000100004\&lng=en\&nrm=iso

Moura, M. L. S. de, Ferreira, M. C., e Paine, P. A. (1998). Manual de elaboração de projetos de pesquisa. Rio de Janeiro: EDUERJ.
Neves, C. M. C. (2003). Referenciais de Qualidade para Cursos a Distância. Brasília: Ministério da Educação, Secretaria de Educação a Distância.

Oliveira, G. P. de. (2010). Estratégias multidimensionais para a avaliação da aprendizagem em cursos online. Ensaio: aval. pol. públ. Educ., 18(66), 05-138. Recuperado de: http://www.scielo.br/scielo. php? script $=$ sci arttext\&pid $=$ So104 40362010000100007\&lng=en\&nrm=iso

Rozenfeld, C. C. F. (2013). Planejamento de cursos online para professores de alemão: parâmetros em mapa conceitual. Pandaemonium ger., 16(22), 279-303. Recuperado de: http://www.scielo.br/scielo. php? script $=$ sci arttext $\&$ pid $=\mathrm{S} 1982$ $88372013000200014 \& \operatorname{lng}=$ en\&nrm $=$ iso Santos, A. N., e Mercado, L. P. L. (2010). Arquivamento e comunicação de imagens radiológicas na formação médica online. Rev. bras. educ. med. 34(4), 525-534. Recuperado de: http://www.scielo.br/scielo php? script $=$ sci arttext\&pid $=$ So100$55022010000400007 \& \operatorname{lng}=$ en\&nrm=iso Teixeira, D. E. et al. (2015). Avaliação institucional em Ciências Biológicas nas modalidades presencial e a distância: percepção dos egressos. Ensaio: aval. pol. públ. Educ., 23(86) 159-180. Recuperado de: http://www.scielo.br/scielo. php? script $=$ sci arttext\&pid $=$ S0104$40362015000100159 \& \ln g=$ en\&nrm $=$ iso 


\section{PERFIL ACADÊMICO E PROFISSIONAL DAS AUTORAS}

Adriana Aparecida de Lima Terçariol. Doutora em Educação e Currículo pela Pontifícia Universidade Católica de São Paulo. Mestre e Pedagoga pela Faculdade de Ciências e Tecnologia Unesp/Campus de Presidente Prudente/SP. Possui experiência em EaD como Coordenadora de Núcleo de Educação a Distância no Ensino Superior, Produção de Materiais Didáticos, Formação/Atuação como Professores/Tutores. Professora na Graduação e Pós-Graduação nas disciplinas: Tecnologias Aplicadas à Educação; Educação a Distância; Formação de Professores; Metodologia da Pesquisa, Avaliação, entre outras áreas. Atualmente é docente no Curso de Pedagogia (Presencial/Distância) na Universidade Nove de Julho (UNINOVE-SP). Docente, Pesquisadora e Líder do Grupo de Estudos e Pesquisas em Educação, Currículo e Tecnologias- GEPECeT no Programa de Pós-Graduação - Mestrado em Educação na Universidade do Oeste Paulista (UNOESTE-Presidente Prudente-SP).

E-mail: atercariol@gmail.com

Elisangela Aparecida Bulla Ikeshoji. Graduada em Administração pela Universidade Estadual de Maringá (1998). Especialização em Gestão de Recursos Humanos pelo Centro Universitário Claretiano (2013). Curso Superior de Formação Pedagógica de Docentes para a Educação Profissional de Nível Médio na Modalidade à Distância, pelo Instituto Federal de Educação, Ciência e Tecnologia de São Paulo - IFSP (2013). Especialização em Teologia pela Pontifícia Universidade Católica do Paraná (2007). Mestranda em Educação na Universidade do Oeste Paulista (Unoeste).

E-mail: elisangela.bulla@gmail.com

Jeong Cir Deborah Zaduski. Graduada em Comunicação Social pela Universidade Federal de Mato Grosso do Sul (2005) e mestrado em Mediazione e Comunicazione Interculturale obtido na Università degli Studi di Verona (2009). Em 2015, mestranda em Educação na Universidade do Oeste Paulista (Unoeste). Tem experiência em Tutoria na Educação a Distância, Traduções e Ensino de inglês e italiano. Pesquisadora em Comunicação entre Pares, Educação a Distância e Educomunicação.

E-mail: deborah zaduski@hotmail.com 
Ana Lucia Farão Carneiro Siqueira. Graduada em Ciência da Computação pela Universidade do Oeste Paulista (Unoeste/1996), especialista em Educação a Distância pelo SENAC-Curitiba/PR (2010). Especialista em Inovação e Gestão em EAD pelo Departamento de Administração da Faculdade de Economia, Administração e Contabilidade de Ribeirão Preto, FEA-RP/USP INEPAD (2013-2015). Mestranda em Educação na Universidade do Oeste Paulista (Unoeste/SP).

E-mail: anasiqueir@gmail.com

Fernanda Sutkus de Oliveira Mello. Graduada em Educação Artística com ênfase em Computação Gráfica pela Universidade Norte do Paraná (1999), especialista em Desenvolvimento de Software para Internet (2003) e especialista em Design Instrucional para cursos virtuais. Mestranda em Educação e Docente na Universidade do Oeste Paulista (Unoeste/SP). Tem experiência na área de Interface e desenvolvimento de Web Site, aplicação de Usabilidade, Ergonomia e Acessibilidade. Experiência na área da educação a distância na criação e elaboração de material didático e tutoria.

E-mail: mello.fer@gmail.com

\section{ENDEREÇO DAS AUTORAS}

Universidade do Oeste Paulista (Unoeste - Campus Ii)

Pós-Graduação - Mestrado em Educação

Rodovia Raposo Tavares, km 572 - Bairro Limoeiro

Presidente Prudente - SP - Brasil

CEP: $19.067-175$

Fecha de recepción del artículo: 04/06//2015

Fecha de aceptación del artículo: 22/09/2015

\section{Como citar este artigo:}

Lima Terçariol, A. A. de, Bulla Ikeshoji, E. A., Zaduski, J. C. D., Carneiro Siqueira, A. L. F., y Oliveira Mello, F. S. de. (2016). As dimensões da avaliação em cursos online: reflexões e importância. RIED. Revista Iberoamericana de Educación a Distancia, 19(2), pp. 283-300. doi: http://dx.doi.org/10.5944/ried.19.2.14753 